\title{
Using a Relational Models Perspective to Understand Normatively Appropriate Conduct in Ethical Leadership
}

\author{
Steffen R. Giessner and Niels van Quaquebeke
}

in press, Journal of Business Ethics

\begin{tabular}{|l|l|}
\hline \multicolumn{2}{|l|}{ ERIM REPORT SERIES RESEARCH IN MANAGEMENT } \\
\hline ERIM Report Series reference number & ERS-2011-002-ORG \\
\hline Publication & February 2011 \\
\hline Number of pages & 32 \\
\hline Persistent paper URL & http://hdl.handle.net/1765/22721 \\
\hline Email address corresponding author & sgiessner@rsm.nl \\
\hline Address & Erasmus Research Institute of Management (ERIM) \\
& RSM Erasmus University / Erasmus School of Economics \\
& Erasmus Universiteit Rotterdam \\
& P.O.Box 1738 \\
& 3000 DR Rotterdam, The Netherlands \\
& Phone: + 31 10 408 1182 \\
& Fax: $\quad+31104089640$ \\
& Email: info@erim.eur.nl \\
& Internet: $\quad$ www.erim.eur.nl \\
\hline
\end{tabular}

Bibliographic data and classifications of all the ERIM reports are also available on the ERIM website: www.erim.eur.nl 


\section{ERASMUS RESEARCH INSTITUTE OF MANAGEMENT}

\section{REPORT SERIES}

\section{RESEARCH IN MANAGEMENT}

\begin{tabular}{|l|l|}
\hline ABSTRACT AND KEYWORDS \\
\hline Abstract & $\begin{array}{l}\text { To describe leadership as ethical is largely a perceptional phenomenon informed by beliefs } \\
\text { about what is normatively appropriate. Yet there is a remarkable scarcity in the leadership } \\
\text { literature regarding how to define what is "normatively appropriate". To shed light on this issue, } \\
\text { we draw upon Relational Models Theory (Fiske: 1992, Psychological Review, 99, 689-723), } \\
\text { which differentiates between four types of relationships: communal sharing, authority ranking, } \\
\text { equality matching, and market pricing. We describe how each of these relationship models } \\
\text { dictates a distinct set of normatively appropriate behaviors. We argue that perceptions of } \\
\text { unethical leadership behavior result from one of three situations: a) a mismatch between leader's } \\
\text { and follower's relational models, b) a different understanding about the behavioral expression, or } \\
\text { preos, of the same relational model, or c) a violation of a previously agreed upon relational } \\
\text { model. Further, we argue that the type of relational model mismatch impacts the perceived } \\
\text { severity of a transgression. Finally, we discuss the implications of our model with regard to } \\
\text { understanding, managing, and regulating ethical leadership failures. }\end{array}$ \\
\hline Free Keywords & ethical leadership, ethics, morality, relational models theory, transgression, regulation, violation \\
\hline Availability & $\begin{array}{l}\text { The ERIM Report Series is distributed through the following platforms: } \\
\text { Academic Repository at Erasmus University (DEAR), DEAR ERIM Series Portal } \\
\text { Social Science Research Network (SSRN), SSRN ERIM Series Webpage } \\
\text { Research Papers in Economics (REPEC), REPEC ERIM Series Webpage }\end{array}$ \\
\hline Classifications & $\begin{array}{l}\text { The electronic versions of the papers in the ERIM report Series contain bibliographic metadata } \\
\text { by the following classification systems: } \\
\text { Library of Congress Classification, (LCC) LCC Webpage } \\
\text { Journal of Economic Literature, (JEL), JEL Webpage } \\
\text { ACM Computing Classification System CCS Webpage } \\
\text { Inspec Classification scheme (ICS), ICS Webpage }\end{array}$ \\
\hline
\end{tabular}


RUNNING HEAD: Relational Models and Ethical Leadership

Using a relational models perspective to understand normatively appropriate conduct in ethical leadership

Steffen R. Giessner \& Niels van Quaquebeke

Rotterdam School of Management, Erasmus University

in press, Journal of Business Ethics 


\begin{abstract}
To describe leadership as ethical is largely a perceptional phenomenon informed by beliefs about what is normatively appropriate. Yet there is a remarkable scarcity in the leadership literature regarding how to define what is "normatively appropriate". To shed light on this issue, we draw upon Relational Models Theory (Fiske: 1992, Psychological Review, 99, 689-723), which differentiates between four types of relationships: communal sharing, authority ranking, equality matching, and market pricing. We describe how each of these relationship models dictates a distinct set of normatively appropriate behaviors. We argue that perceptions of unethical leadership behavior result from one of three situations: a) a mismatch between leader's and follower's relational models, b) a different understanding about the behavioral expression, or preos, of the same relational model, or c) a violation of a previously agreed upon relational model. Further, we argue that the type of relational model mismatch impacts the perceived severity of a transgression. Finally, we discuss the implications of our model with regard to understanding, managing, and regulating ethical leadership failures.
\end{abstract}

Key words: Ethical Leadership, Ethics, Morality, Relational Models Theory, Transgression, Regulation, Violation

Word count: 6628 


\section{Using a relational models perspective to understand "normatively appropriate conduct" in ethical leadership}

In light of recent ethical failures spanning private and public organizations, research has increasingly focused on the issue of ethics in organizational leadership (Brown et al., 2005; De Hoogh and Den Hartog, 2008, 2009; Den Hartog \& De Hoogh, 2009; Jones, Felps, \& Bigley, 2007; Kanungo, 2001; Treviño et al., 2003; Turner et al., 2002). This renewed interest goes hand in hand with evidence that leadership does indeed play a critical role in ethical shortcomings both on the grand scale and even on more so at the day-to-day level (Mayer et al., 2009). Notably, ethical leadership has not only been studied as a normative issue, but also shown to have direct positive consequences for leadership effectiveness, followers' job satisfaction, and organizational citizenship behavior (Brown et al., 2005; Kalshoven et al., in press). Thus, to determine how to regulate and change organizational behavior to fulfill certain moral and ethical standards, it is widely suggested that scholarship develop a better understanding of the psychological dynamics at play (Brown and Treviño, 2006).

Although theories on transformational leadership (Bass, 1985; Bass and Riggio, 2006) and servant leadership (Greanleaf, 1977; Liden et al., 2008) partly account for ethical aspects of leadership, researchers have only recently focused on ethical leadership in particular (Brown and Treviño, 2006; Brown et al., 2005; De Hoogh and Den Hartog, 2008; Neubert et al., 2009; Treviño et al., 2003). Currently, perhaps the most influential definition of ethical leadership stems from Brown and Treviño (2005), who draw upon social learning theory (Bandura, 1977, 1986) to argue that ethical leadership entails credibly modeling normatively appropriate conduct. Yet, while this definition leaves little to argue with, it also provides little to work with because "normatively appropriate" is a rather vague term. For example, is it ethical when an otherwise friendly leader suddenly threatens to fire an employee for taking days off to care for a sick child? 
Or, is it ethical when a stellar employee has been promised a performance bonus, but then is not paid the bonus because the team as a whole experienced a dramatic loss? Answering these questions requires an understanding of the type of relationship between leader and follower. Thus, we consider it crucial to complement Brown's and Treviño's perspective on ethical leadership by defining more precisely what "normatively appropriate" entails (cf. Klein, 2002; Trevino and Weaver, 2003). To do so, we draw upon Relational Models Theory (Fiske, 1991, 1992, 2004), defining salient relationship models and exploring how these affect perceptions of ethicality. In this paper, we focus on the perspectives of followers and other stakeholders. Further, we focus on norm transgressions and consequent evaluations of unethical leadership rather than norm fulfillment and its ethical interpretation (cf. van Gils et al., in press).

Our research has various implications. First, our analysis corroborates the argument of Brown and colleagues (2005) that the core issue of ethical leadership is not about a particular type of leadership but rather about fulfilling normative standards embedded within relationships between leaders and stakeholders. Second, our approach helps to distinguish between three types of "unethical leadership" perceptions: a) those due to different relational models between leader and follower, b) those due to different behavioral expressions of the same relational model, and c) those due to a violation of a previously agreed upon relational model. Third, our analysis explores when and how such relationship transgressions might be more or less unethical.

In this paper, we first briefly review prominent perspectives leadership scholarship takes on ethical leadership. Next, we introduce Relational Models Theory and explain how this theory can elucidate various norms that may underlie relationships. Finally, we bring these two strands together in an analysis of what is "normatively appropriate" in leader-follower relationships and outline novel ideas that can be derived from this research.

\section{Ethical Leadership}


To date, the literature includes several theoretical conceptualizations of ethical leadership and its fundamental processes. Our perspective follows prior convention in defining leadership as "a process of social influence in which one person is able to enlist the aid and support of others in the accomplishment of a common task" (Chemers, 2000, p.27). Using this definition, some leadership theories treat ethical behavior as one specific dimension within a broader conception of leadership. For instance, servant leadership theory focuses on the leader's ability to develop employees to their fullest potential (Greanleaf, 1977; van Dierendonck, in press). Servant leadership theory conceptualizes leaders as servants of their followers, placing their followers' needs above their own needs. In this respect, a recent measure by Liden and colleagues (2008) explicitly specifies ethical behavior as a central dimension of servant leadership among other dimensions such as emotional healing, creating values for the community, conceptual skills, empowering, helping followers grow and succeed, and putting followers first.

Likewise, ethical leadership is integral to transformational leadership theory. Transformational leaders inspire followers to transcend self-interest and serve collective values and goals, motivating followers to achieve exceptional performance (Bass, 1985; Bass and Avolio, 1993; Burns, 1978; Conger and Kanungo, 1987). Bass and Avolio (1993) described four dimensions of transformational leaders: inspirational motivation, idealized influence, individualized consideration, and intellectual stimulation. The idealized influence dimension of transformational leadership is closely related to ethical leadership because it is defined as the leader's modeling of high standards in the domain of ethics and morality (Bass \& Steidlmeier, 1999).

Recently, Brown and colleagues (2005; Brown and Trevino, 2006) developed a leadership theory focused on explaining ethical leadership. They argue that although transformational leadership is often ethical, there can be cases (i.e., charismatic dictators) in which 
transformational leaders are widely considered unethical (Bass, 1985). Furthermore, transactional leadership (i.e., a leadership type based on contingent rewards and management-by-exception), which is often described as the antithesis of transformational leadership, can be used by ethical leaders to reinforcement positive behaviors through rewards and punishments (Gini, 1998; Kanungo, 2001; Trevino et al., 2003). Brown and colleagues thus conclude that the ethicalunethical dimension does not altogether correspond to the framework of transformational vs. transactional leadership. Instead, they approach the issue from a social learning perspective (Bandura, 1977, 1986). They argue that a leader has to be a credible role model of normatively appropriate behavior. To do so, the leader might make use of not only transformational behaviors but also transactional ones, such as the use of reward and punishment to stimulate ethical conduct (Brown et al., 2005; Mayer et al., 2009; Treviño et al., 2003). Specifically, Brown and colleagues (2005) define ethical leadership "as the demonstration of normatively appropriate conduct through personal actions and interpersonal relationships, and the promotion of such conduct to followers through two-way communication, reinforcement, and decision-making” (p. 120). Based on this perspective, various measures of ethical leadership have been developed that include dimensions such as fairness, power sharing, and role clarification (De Hoogh and Den Hartog, 2008, 2009), or character and integrity, community/people-orientation, motivation, encouragement and empowerment, ethical awareness, and accountability (Resick et al., 2006).

\section{Norms in Relationships}

In line with Brown and colleagues' (2005) contention that normatively appropriate conduct plays out via interpersonal relationships, we turn to a social relational framework to understand what is considered normatively appropriate. Although there are several theoretical perspectives on social relations (e.g., Clark and Mills, 1979; Foa and Foa, 1974), we build upon Fiske’s Relational Models Theory (RMT; Fiske, 1991, 1992; 2004) because it (a) provides a 
comprehensive and exhaustive taxonomy of social relations that can be found across cultures, (b) has received empirical support in different research domains using quantitative and qualitative methods (for a comprehensive overview see Haslam, 2004). Finally, (c) this taxonomy directly addresses coordination norms that define boundaries of acceptable moral behavior (Bolender, 2003; Fiske, 1991; Goldman, 1993; Goodenough, 1997; Rai and Fiske, in press; Sunar, 2009). RMT postulates four basic mental models, or cognitive schemas, that humans use to structure and coordinate everyday social interactions - communal sharing (CS), authority ranking (AR), equality matching (EM), and market pricing (MP). Based on anthropological, sociological and psychological findings, Fiske (1991, 2004) asserts that these mental models exist to some extent in all cultures and are universally rooted in the human mind. In other words, he predicts that these relationships are to a certain degree innate. Moreover, it is important to note that even though all of these relational models possess a qualitatively distinct mental model (Fiske, 1991, 1992, 2004), all RMs define moral standards and ethical considerations that are internally perceived as fair and legitimate. Before discussing the value of this theoretical approach for our understanding of ethical leadership, we think that the four elementary models first need to be described in a little more detail (see Table 1 for a summary):

Table 1 about here

Communal sharing (CS) refers to a mental model that focuses on what group members have in common, what they share, and what differentiates them from those outside the group. People who share a CS relationship experience equivalence and tend to own all resources to the same degree. There is no differentiation between members within a CS relationship. Thus, people are undifferentiated and equivalent within this relational model, but differ from people outside this relationship (i.e., categorical distinction). People sharing a CS mental model follow a "onefor-all and all-for-one" morality. The members of this relationship can simply take things 
according to their needs (cf. Deutsch, 1975) and give things according to their own abilities. They show altruism, love and care.

Authority ranking $(A R)$ is the mental model we use when we rank or order individuals along a certain dimension (e.g., age, gender, seniority, or legitimate organizational structures). This mental model underlies the structuring of asymmetrical interactions according to ordered differences - that is, power relations - and as such is the basis for status, rank, and hierarchies (i.e., ordinal structures). People sharing an AR mental model follow a "noblesse oblige" morality - they show respect and loyalty to higher ranks and provide security and protection to lower ranks. A higher-ranking person commands a larger share of resources than a lower-ranking person.

Equality matching (EM) is characterized by balanced reciprocities (i.e., things have to be equal). More precisely, this mental model entails a "tit-for-tat" morality with egalitarian norms and one-for-one or eye-for-an-eye exchanges. People using this mental model focus on additive interval differences for their units of exchange in order to achieve balance (i.e., interval comparisons). In other words, if one receives a unit of exchange (e.g., an invitation for a dinner from a colleague), one is expected to balance this unit with a similar unit of exchange (e.g., a reciprocal dinner invitation). As a result, people within this relationship model strive for equal treatment or reciprocal revenge.

Market pricing $(M P)$ is a mental model that organizes interactions with reference to proportionality in the relationship. More precisely, individuals attend to rates or ratios and make cost-benefit calculations. In MP relationships, individuals reduce all relevant features and components of the relationship into a single value or utility metric. In this way, people can compare different types of commodities. For instance, money is a common metric used by buyers and sellers in a marketplace. Similar cost-benefit calculations in social or justice contexts also use 
a common metric (e.g., how does my work input relate to the reward I get; see Adams, 1965). In this mental model, the person possessing most of the common metric (e.g., money) can get the most value in other commodities (e.g., buy more or better food, car, etc.). Thus, the morality reflected in MP is "the greatest good for the wealthiest". The interested reader can find more details about these mental schemas in the books of Fiske (1992) and Haslam (2004).

The CS model is the least complex model as it provides only categorical differentiations (i.e., either you belong to the collective or not) whereas the MP model is the most complex schema, based on ratios and an agreed upon "currency". AR uses rank orders as its underlying metric and EM uses interval comparisons including subtraction and addition to ultimately decide what is equal. Thus, AR and EM can be seen as occupying an intermediate level of complexity. This implies that the more complex RMs require more complex structures to achieve agreement among actors. This ordering of the RMs corresponds to the ontogenetic timing whereby children begin to display the RMs. CS seems to be displayed in infancy, AR and EM around the age of 3 to 4, and MP around the age of 9 (Fiske, 1991, 1992).

The exact enactment of these mental models, i.e., how they are expressed in relationships, is culture-specific (i.e., ethnic, organizational, situational culture etc.). For example, differences in hierarchies in an AR mental model might be displayed differently between ethnic or organizational cultures, e.g., employees of some organizations might use a very formal language to talk to a higher status person whereas this might not be appropriate in other organizations. Similarly, some Asian cultures use more indirect forms of communication in establishing hierarchy whereas Western cultures tend to use more direct communication in hierarchical relationships (Gudykunst, 2001). Thus, the cultural context of the relational model determines the exact implementation rules, or preos, to enact the relationship. 
Furthermore, people rarely use a single mental model exclusively in any given situation. Typically, we use a combination of the four mental models to coordinate our interactions in actual relationships. For example, colleagues may share a printer freely with each other (CS), work on a project in which one of them is the expert and takes the lead (AR), divide the office space equally (EM), and sell each other working hours for an agreed amount of money (MP). However, although the models can be combined in different ways, there is often a primary model that significantly defines a given relationship, allowing other relationships to be "nested" within this more general relationship (Connelley and Folger, 2004; Fiske and Tetlock, 1997). Therefore, in the current paper, we assume that each leader/follower relationship uses one primary RM of interaction and coordination.

\section{Using The RMs Perspective To Understand "Normatively Appropriate Conduct" in Ethical Leadership}

What are the implications of RMs for followers' perceptions of ethical leadership? On first blush, one might assume that only the AR model is of importance to leadership. However, leadership needs to be understood as a more complex process than mere influence by authority, a process that can involve various types of relationships between leaders and followers (Avolio et al., 2009; Chemers, 2001). Moreover, because each RM represents a distinct mental model for coordinating, organizing, and evaluating all aspects of a relationship, we contend that all four RMs play a central role in understanding when and how persons are considered "normative" role models. In essence, each of the four RMs defines a different kind of morality that the relationship partners might live by (Fiske, 1991; see Table 1). In the following section, we explore the underlying moralities of the RMs and explain how RMs might influence different ethical leadership types.

\section{Linking RMT with Ethical Leadership}


As outlined above, CS implies altruism between relationship members - sharing resources generously with other members, caring for members and fulfilling other members' needs (Fiske, 1991, 1992, 2004). Overall, the CS mental model strongly resembles common definitions of ethical leadership. For instance, ethical leadership defined as individualized consideration by transformational leadership reflects a leader's attention to the individual needs of followers (Bass, 1985). This attention to followers' needs is not based on an exchange process but rather involves a certain degree of caring for team members, reflecting a CS relationship. Similarly, altruism and “concern for others" have been used as dimensions in defining ethical leadership (De Hoogh and Den Hartog; Resick et al., 2006). These dimensions also represent core behavioral elements of CS. Importantly, these CS behaviors apply only to members of a common group and do not hold for individuals outside this group. Likewise, servant leadership theory (Greenleaf, 1991; Russell and Stone, 2002; van Dierendonck, in press) emphasizes CS characteristics such as empathy, community building, and caring as reflected in listening and healing. Caring for others is also a central part of Brown and colleagues' (2005) ethical leadership conceptualization, as they assume caring is the basis on which a leader becomes a credible role model (Bandurra, 1986; Brown and Trevino, 2006). In essence, the CS relational model suggests that altruism defines what is normatively appropriate (Brown et al., 2005). In this mental model, followers perceive ethical leadership when they feel they belong to a common group with their leaders. In the ideal CS scenario, resources (e.g., time, needs) are shared according to need and leaders care for and show altruistic behavior towards their employees.

In contrast, AR entails a "noblesse oblige" morality in which the leader offers security, protection, and guidance to followers in return for their respect, loyalty, and obedience. Importantly, AR does not entail a coercive leader-follower relationship such as an authoritarian dictatorship. Rather, that the ideal leader according to the AR mental model is perceived as 
charismatic (cf. Weber, 1978) and as a positive, almost parental, figure by followers. Again, certain aspects of this relationship model appear in common definitions of ethical leadershipaspects that are qualitatively different from those that characterize CS (Fiske, 1992, 2004). For instance, Brown and colleagues (2005; Brown and Trevino, 2006) argue that leaders should be role models and guide followers partly based on power and status. This notion of the leader's need for credibility as a role model is based on an AR mental model of the follower. In this model, the follower needs to understand that the leader possesses legitimate power to guide followers and to define appropriate behaviors in a given situation. Furthermore, the AR relational model justifies a system in which leaders command more resources (e.g., bigger offices, higher salaries) based on hierarchical position. In return, AR leaders assume greater responsibilities in terms of guidance and protection of followers (e.g., set a vision, provide followers with resources according to rank, establish a clear hierarchy structure, maintain a social order that is accountable for everyone). In sum, the guiding fairness principle of the AR model comprises equity between power and responsibility on the one side and rewards on the other.

The basis of morality in EM relationships is a tit-for-tat logic that emphasizes equal treatment and reciprocal revenge. In the EM mental model, followers want leaders who balance things out and engage in turn-taking behavior. As an example, if the follower helps out the leader during the finalization of a project by working overtime, the leader can balance this out by thanking the employee privately and/or publicly or reducing the follower's future work load accordingly. What types of behavior are considered equal depends on the implementation rules (i.e. preos) dictated by the cultural context. The tit for tat logic of the EM model is regulated by followers as well as leaders. For example, if a follower thinks that the leader fails to provide sufficient task effort, the follower might compensate by decreasing performance. In essence, to become a credible ethical leader role model within the context of the RM mental model, 
leadership must be even-handed and provide equal opportunities, equal voice, and equal contributions.

Finally, the MP mental model entails a complex capitalist morality. This mental model makes ratios (i.e., proportions) meaningful. Followers calculate costs and benefits and strive to maximize gains. The negotiated contracts or rules of a market define the metrics and regulations for an interaction. These contracts and rules form the basis for moral obligations and the evaluation of transgressions. Adherence to procedures is crucial to the MP mental model. Leadership within this framework is implemented through the negotiation of a contract between the follower and the leader. Normative behavior must follow these negotiated rules. In essence, the MP relationship can be conceived as a more complex version of the simple EM relationship. In the MP model, participants need specifications for a common utility metric, of which money is the prototypical example. Followers make cost-benefit calculations to determine their actions. Thus, leaders might offer followers an extra monetary bonus to influence their behaviors or threaten to freeze bonuses until performance meets expectations. Although this RM does represent a morality of its own, it is relatively disconnected from the ethical leadership literature, perhaps because self-interest rank rather low in Kohlberg's (1981) pyramid of moral development. Yet, when a relationship is governed by the MP model, transgressions are still considered unethical.

Although certain RMs are more traditionally associated with ethical leadership ${ }^{1}$ than others, it becomes evident upon reflection that ethical leadership in daily life is affected by each of the four RMs. This reasoning is in line with Brown's and colleagues' (2005) argument that ethical leadership should not simply be equated with transformational leadership. The RMs define what is fair (Connelley and Folger, 2004; Fiske, 1992) and represent relevant normative standards used by followers in evaluating leaders. By studying the normative standards defined 
by the four RMs, we can extend ethical leadership theory by defining more precisely the normative element in ethical leadership perceptions. In addition, our conceptualization diverges from the popular view that ethical leadership is necessarily based on a caring or altruism (Brown and Trevino, 2005; De Hoogh and Den Hartog, 2008, 2009 Resick et al., 2006). When considering the prevalence of all four RMs in everyday life, it becomes apparent that many previous theoretical approaches, as well as popular opinion on ethical leadership, overemphasize the CS mental model. In our conception, all of these mental models independently define moral judgments, fairness consideration, and ethical ideologies (cf. Fiske, 1992, 2004; Sunar, 2009; Tetlock and Fiske, 1997). We thus propose that followers perceive their relationships with a given leader based on one of the four $\mathrm{RMs}^{2}$ and base their judgments of normatively appropriate leadership behavior on the norms prescribed by that RM. Essentially, leaders gain credibility as role models of moral conduct by fulfilling the norms of the appropriate mental model for the specific leader-follower relationship (cf. Brown and Trevino, 2006; Brown et al., 2005).

Proposition 1. The RMs Communal Sharing, Authority Ranking, Equality Matching, and Market Pricing represent qualitatively different coordination norms and standards by which followers judge ethical leadership.

\section{Types of Norm Violation, i.e. Unethical Leadership}

As Brown and colleagues (2005) argue, ethical leaders need to be trusted and credible role models. Therefore, violations of relationship norms are likely to undermine this trust and thus reduce the perception of ethical leadership. In fact, we contend that leaders' failure to fulfill norms is a more salient contributor to followers' ethical perceptions of leadership than the fulfillment of norms (van Gils et al., in press). Speaking of ethical leadership sets a misleading focus because ethical leadership is norm-appropriate conduct and thus will hardly be recognized in the social sphere. Indeed, previous research shows that bad events are more informative than 
good events (Baumeister et al., 2001). Therefore, we prefer to focus on unethical leadership, as it represents norm transgression and thus triggers the discussion at hand.

We propose that a perceived norm violation by a leader can have three distinct causes.

First, leaders and followers might emphasize different RMs within their common relationship. As a result, the leader's behavior might be in accordance with the norms of the RM salient to the leader yet violate the norms of the RM salient to the follower. Such a violation can easily occur as the leader and the follower might construct their relationship in different areas of interaction with different RMs (cf. Fiske, 1992; Fiske and Tetlock, 1997). Indeed, it is often the case that confusion and conflict exist over which relational model to apply in a given situation (Whitehead, 1993). Followers and leaders might form their expectations of the appropriate RM based on a former interaction with the leaders or followers, prior cultural or educational experience, received wisdom about leadership, the prevalent RM within the organizational culture and structure, and situational needs.. For instance, a follower might be accustomed to a leader who cares for the needs of each employee (i.e. CS), but the current leader might use a MP mental model and only award commodities (e.g., money, extra vacation days, awards) to employees according to their performance.

Second, while RMs represent discrete mental models for organizing, coordinating and evaluating relationships, the behavioral implementation, or preos, of these models can vary as well (Fiske, 1992; Tetlock and Fiske, 1997). In this respect, the preos of a leader and a follower from different cultures or age groups might differ and lead to disagreements about what constitutes ethical leadership in a given situation. For example, a leader might try to convince a follower to do an additional task within an EM relationship. To do so, the leader might explain that fulfillment would result in a nomination for the employee of the month award - an established gesture of recognition within the company. However, the employee, freshly hired 
from a different company, might have become accustomed to receiving an extra vacation day for this type of request and thus the offer might be interpreted as inappropriate. In this case, although both parties share the same RM mental model, they fail to agree on the correct behavioral expression of that RM.

A third type of violation can result if both actors agree upon their RM and the implementation rule, but one actor violates the rule stipulated by the RM. Such a violation of normative behavior can be either intentional (i.e., egoistic motives, evil) or unintentional (i.e. simple carelessness or misinterpretation of a situation) (Fiske, 1991; Tetlock and Fiske, 1997).

Proposition 2. There are three distinct causes of the perception of unethical leadership:

a) The leader and follower hold different RMs regarding their relationship. b) The leader and follower hold different preos, leading to conflicting interpretations of the proper behavioral expression of the same RM. c) The leader violates the RM either intentionally or unintentionally.

\section{Severity of Norm Violations}

RMT assumes that the RMs can also differ in moral significance, social value, and motivational strength. Although these differences vary by person, context, content and culture, there seems to be a general tendency such that the RMs can be ordered as follows: CS > AR > EM > MP (Fiske, 1991; Fiske and Tetlock, 1997). This normative ranking of the RMs corresponds to their relational complexity and ontogenetic emergence. Furthermore, this ordering aligns with the fact that most theories on ethical leadership heavily emphasize CS elements such as altruism and the leader's care for followers (cf. Bass and Avolio, 1993; Brown et al., 2005; De Hoogh and Den Hartog, 2008, 2009). However, this moral and motivational ordering of the RMs should be regarded only as a general tendency and not an invariant rule. Nevertheless, following our propositions 1 and 2, we maintain that although the RMs can vary in their moral significance, 
each RM still represents a distinct morality that can serve as a basis of ethical leadership (cf, Haslam, 2004; Fiske, 1991, 1992).

However, such ordering of the RMs in terms of moral and motivational strength has implications on perceptions of moral transgressions. More precisely, Fiske and Tetlock (1997) argue that distress and the outrage of an explicit trade-off among the RMs depends on the distance and direction of the moral and motivational ordering of the models. For example, they argue that people tend to perceive violations from CS to MP as more stressful than violations in the opposite direction. Applying this to the leadership domain, a leader with a history of helping followers develop their competencies and using time resources to fulfill the needs of each follower (i.e., an established CS relationship), could be perceived as unethical if he or she suddenly introduced a system in which followers could only meet with the leader by paying points earned via a new performance evaluation system (i.e., MP behavior). In contrast, a leader who changes in the opposite direction (i.e., from MP to CS behavior) would likely elicit less distress in his/her followers. Note that the employees in this case are still likely to experience some amount of stress since they were used to the MP system and might therefore distrust that the new relationship with the leader will be effective.

Furthermore, the distance between the RMs also matters (Fiske \& Telock, 1997). A violation from CS to MP is typically perceived as more stressful than a violation from CS to EM. Using the example from above, the described change from CS to MP is more stressful compared to a change in which the leader now provides more meeting time with followers higher in hierarchy and less meeting time with followers low in rank (i.e., AR). Thus, followers' perceptions of the degree of inter-RM norm violations depends on the direction and distance separating the two salient RMs on the scale. Leaders can more likely "get away" with violating an expected relational model if the distance of the moral asymmetry is rather small. As a result, a 
leader's behavior might be perceived as less stressful and more trustworthy if it changes from AR to $\mathrm{CS}$ rather than from $\mathrm{CS}$ to MP.

This moral asymmetry has been shown in ethnological studies (see Fiske and Tetlock, 1997). In addition, recent empirical studies support the directional and distance assumption in the area of consumer transactions (McGraw and Tetlock, 2005; McGraw et al., 2003). McGraw and colleagues (2003; McGraw and Tetlock, 2005) manipulated the relational ownership history of a product (i.e., whether the product was received via a CS, AR, EM or MP relationship). Next, the researchers provided a proposal to buy the product - thus, providing an MP exchange relationship. Such a proposal was easily accepted for products acquired via an MP relationship, because the MP transaction matched the product's ownership history. But when the product was acquired by one of the other relationships, participants experienced much more distress and placed much more value on the product. Furthermore, distress was highest when ownership was based on a CS relationship (e.g., the product was given to the participant by a close relative). This finding supports the directional assumption of Fiske and Tetlock (1997). However, the results could not fully support the directional hypothesis for AR and EM relationships, suggesting that more research is needed to clarify the directional hypothesis. Furthermore, the research so far has mainly addressed products and not directly the relationships between two persons or, even more specific, the relationship between a leader and a follower. Therefore, the following propositions rest largely on the original theoretical reasoning of Fiske and colleagues (Fiske, 1991, 1992;

Fiske \& Tetlock, 1997).

Proposition 3. If leaders use different RMs than followers expect, followers' unethical leadership perceptions depend on the direction from expected RM to employed RM. The general moral asymmetry is $C S>A R>E M>M P$ in which the direction from $C S$ to $M P$ is perceived as more unethical than vice versa. 
Relational Models and Ethical Leadership 19

Proposition 4. If leaders use different RMs than followers expect, the severity of followers' unethical leadership perceptions depends on the distance between expected $R M$ and employed RM, along the scheme of $C S-A R-E M-M P$.

\section{Discussion and Implications}

The current paper extends ethical leadership theory by applying an RMT perspective to better understand what "normatively appropriate conduct" actually is. Applying this theoretical perspective to the domain of ethical leadership creates several new predictions and insights regarding how leaders should regulate their own leadership behavior in order to be perceived as ethical by their followers. The first important point is that there are four qualitatively different and innate types of relational models that can potentially define what is perceived as normatively appropriate in relationships: CS, AR, EM and MP (see Table 1). These RMs help to coordinate interactions between leaders and followers with the respective salient RM determining how leaders and followers regulate and perceive behavior. For each participant in the relationship, the salient RM depends partly on the personality and motives of the participant as well as the organizational and social context. Therefore, it is not uncommon for confusion and conflict to arise regarding what kind of RM to use when discussing what is ethical in a leadership context (Whitehead, 1993). In consequence, unethical leadership perceptions can result from a non-fit of the RMs used by leader and follower. Likewise, particularly in settings where the preos of the leader and follower are different, perceptions of unethical leadership may stem from different behavioral expressions of the same RM. Last, perceptions of unethical leader behavior can result from an intentional or unintentional violation of a previously agreed upon RM. Finally, we argue that the direction of the transgression as well as the distance between salient RMs both play an important role in the evaluation of ethical leadership (cf. Fiske, 1991; Fiske and Tetlock, 1997). 
This prediction is especially interesting, because leaders might experience certain dilemmas that cannot be solved within their current RM and, therefore, need to change the RM.

Although the personalities of leaders and followers can directly impact their relationships, organizational structures and organizational culture are likely to pre-define the prevalent RM within an organization (Connelley and Folger, 2004; Fiske and Tetlock, 1997). For instance, in an organization with clear hierarchies, AR relationships are likely to develop. In an organization in which leaders structure tasks via an MP scheme by setting out explicit rules of task goal and accomplishment, MP relationships are likely to develop. Therefore, perceived violations of relational models actually tend to arise more often for people outside the organization in question. While employees within an organizational context tend to adapt quickly to the organization's relational model and preos, outsiders are more likely to apply different relational models when judging a leader's ethics. For instance, bonus payments to investment bankers tend to be judged as unethical from an outside perspective, because, especially in times of crisis, many people believe society should stand together and personal interest should come behind collective interest (a CS relationship). In contrast, investment bankers tend to work on a proportional basis for their bonuses (an MP relationship), and according to MP norms, bankers who made profits deserve their bonuses.

Our approach provides an understanding of the normative appropriateness of leadership behavior and seeks to understand the conditions when people perceive that salient relationship norms have been violated, specifically regarding perceptions of unethical leadership. Many theories on ethical leadership place a strong emphasis on the role model function of ethical leaders (Brown and Trevino, 2006; De Hoogh and Den Hartog, 2008, 2009). Our perspective can be understood as complementing these descriptive perspectives in that each RM represents a normative background on which a leader can be evaluated and can potentially earn or lose the 
credibility to act as a role model. Importantly, however, our perspective clarifies that the CS model of caring and altruistic leadership is not the only basis for ethical leadership, although it does have stronger moral significance than the other relational models.

As a result, our analysis suggests that ethical leadership should not necessarily be measured by a set list of behaviors or characteristics (e.g., Brown et al., 2005; De Hoogh and Den Hartog, 2008, 2009; Resick et al., 2006), but rather measured as a degree of RM (mis)match between what a follower expects from a leader and how the leader acts. As such, the discourse around ethical leadership shifts away from specific behaviors and toward an exploration of the salient mental models held by leaders versus followers.

Another implication involves the issue of trust repair - or how to regulate ethical failures (Dirks et al., 2009; Kim et al., 2004). As described in Proposition 2, we contend that perceived unethical leadership can have three distinct causes. Depending on the cause, different forms of amendment might be possible. In the first case (i.e., different RMs) the problem is that both actors believe they have acted in an ethically correct way and, consequently, both tend to deny ethical misconduct. Trust can be repaired if the leader works with the follower to clarify the underlying RMs on which they have based their decision or behavior how both parties would like to handle their relationship in the future. As part of such negotiations, each party might be able to convince the other party that their own doing was not motivated by ill will (Kim et al., 2004). However, to repair trust after such a case might be the most difficult, as the leader believes she/he has acted correctly and thus might have trouble grasping the underlying cause of the norm violation. In the second case (i.e., different preos), the problem may be solved via metacommunication about the correct behavioral expressions of a relationship. Since there is fundamentally no misunderstanding on the underlying RM, both parties just need to be able to follow each other's logic in the expression of the RM and how their actions are linked to the 
mental models. As in the above case, the challenge here, lies in making leader and follower aware of the different behavioral interpretation of the relational model. Finally, in the third case (i.e., the violation of a previously agreed upon RM and preos), the violation cannot be justified. However, this is the case in which the transgression should be more obvious to the leader than in the other two cases. Therefore, it is most likely that the leader can and will regulate ethical failures (e.g., via apologizing). However, given that the violation is a genuine violation, it is also likely to be the hardest to repair. In sum, a leader can best prevent perceptions of ethical failure by clarifying the RM and preos of the relationship with followers from the beginning.

Last, the famous linguist and politics consultant George Lakoff (2004) once said with regard to public leadership that it is paramount to "know your values and frame the debate". Indeed, when reanalyzing political debates leading up to presidential elections, he saw that while Democrats may have valid arguments, they were destined to lose as long as they and the news media accepted Republican nomenclature such as "pro-life," "tax relief," and "family values," since to argue against such inherently positive terminology automatically casts the arguer in a negative light. In the context of the current discussion, we might adapt his slogan to "know your relational model and frame the debate". Indeed, judging ethical behavior is largely a perceptual process that is grounded beliefs about what is normatively appropriate. Leaders can work to avoid allegations of ethical misconduct by actively managing others' beliefs about what is appropriate in specific situations.

In this paper, we introduced RMT as a framework for the analysis of ethical leadership. We propose that RMT is a useful perspective for understanding the moral dynamics of what is considered "normatively appropriate" and as such represents a promising framework to further explore the antecedents and consequences of ethical leadership. Moreover, regulating unethical behavior in our conception by and large pertains to the management of RM expectations and their 
according norms. While this perspective might be disappointing from the standpoint of normative ethics (e.g., philosophy that focuses on classical Christian virtues such as bravery, courage, compassion, etc, or consequential philosophy that ultimately arrives at Utilitarianism as the only possible way of conduct), we consider this framework a stringent example of meta-ethical theory. Indeed, within the field of meta-ethics our conception can be described as non-cognitivist. Noncognitivists argue that when someone makes a moral statement, they are not describing the world but rather either expressing their feelings or telling people what to do. As such our perspective is also much like Constructivism in that we do not argue what is right or wrong but rather that determining right from wrong is up to the perceiver. In our conception, the perceiver's salient RM dictates a set of normatively appropriate behaviors against which behavior is judged as ethical or unethical and each of the four RMs dictates a distinct set of moral norms. 


\section{References}

Adams, J. S.: 1965, 'Inequity in Social Exchange', In L. Berkowitz (ed.), Advances in Experimental Social Psychology, (Academic Press, New York, NY), pp. 267-299.

Avolio, B. J., Walumbwa, F. O., and Weber, T. J.: 2009, 'Leadership: Current Theories, Research, and Future Directions', Annual Review of Psychology, 60, 421-449.

Bandura, A.: 1977, 'Social Learning Theory’, (Prentice-Hall, Englewood Cliffs, NJ).

Bandura, A.: 1986, 'Social Foundations of Thought and Action', (Prentice-Hall, Englewood Cliffs, NJ).

Bass, B. M.: 1985, 'Leadership and Performance Beyond Expectations’ (Free Press, New York, NY).

Bass, B. M., and Avolio, B. J.: 1993, 'Transformational Leadership: A Response to Critique', In M. M. Chemers and R. Ayman (eds.), Leadership: Theory and Research Perspectives and Directions (Academic Press, San Diego, CA), pp. 49-80.

Bass, B. M., and Riggio, R. E.: 2006, ‘Transformational Leadership', (Lawrence Erlbaum Associates, Mahwah, NJ).

Bass, B. M, and Steidlmeier, P.: 1999,'Ethics, Character, and Authentic Transformational Leadership Behavior', Leadership Quarterly, 10, 181-218.

Baumeister, R. F., Bratslavsky, E., Finkenauer, C., and Vohs, K. D.: 2001, 'Bad is stronger than good', Review of General Psychology, 5, 323-370.

Bolender, J: 2003, 'The Genealogy of the Moral Modules', Minds and Machines, 13, 233-255.

Brown, M. E., and Treviño, L. K.: 2006, 'Ethical Leadership: A Review and Future Directions', Leadership Quarterly, 17, 595-616. 
Brown, M. E., Treviño, L. K., and Harrison, D. A.: 2005, 'Ethical Leadership: A Social Learning Perspective for Construct Development and Testing', Organizational Behavior and Human Decision Processes, 97, 117-134.

Burns, J. M.: 1978, 'Leadership’ (Harper \& Row, New York, NY).

Chemers, M. M.: 2000, 'Leadership Research and Theory: A Functional Integration’, Group Dynamics, 1, 27-43.

Clark, M. S., and Mills, J.: 1979, 'Interpersonal Attraction in Exchange and Communal Relationships', Journal of Personality and Social Psychology, 37, 12-24.

Conger, J. A., and Kanungo, R. N.: 1987, ‘Towards a Behavioral Theory of Charismatic Leadership in Organizational Settings', Academy of Management Review, 12, 637-647. Connelley, D. L., and Folger, R.: 2004, 'Hidden Bias: The Impact of RMs on Perceptions of Fairness in Human Resource Systems', In N. Haslam (ed.), RMs Theory: A Contemporary Overview, (Lawrence Erlbaum Associates, Mahwah, NJ), pp. 197-220.

De Hoogh, A. H. B., and Den Hartog, D. N.: 2008, 'Ethical and Despotic Leadership, Relationships with Leader's Social Responsibility, Top Management Team Effectiveness and Subordinates’ Optimism: A Multi-Method Study', Leadership Quarterly, 19, 297-311.

De Hoogh, A. H. B., and Den Hartog, D. N.: 2009, 'Ethical Leadership: The Positive and Responsible use of Power', in D. Tjsovold and B. Wisse (eds.), Power and interdependence in organizations (Cambridge University Press, Cambridge, UK), pp. 338-354.

Den Hartog, D. N., and De Hoogh, A. H. B.: 2009, 'Empowerment and Leader Fairness and Integrity: Studying Ethical Leader Behavior: From a Levels-of-Analysis Perspective', European Journal of Work and Organizational Psychology, 18, 199-230.

Deutsch, M.: 1975, 'Equity, Equality, and Need: What determines which Value will be used as the Basis of Distributive Justice?', Journal of Social Issues, 31, 137-149. 
Dirks, K. T., Lewicki, R. J., and Zaheer, A.: 2009, 'Repairing Relationships within and between Organizations: Building a Conceptual Foundation', Academy of Management Review, 34, 401-422.

Fiske, A. P.: 1991, 'Structures of Social Life: The Four Elementary Forms of Human Relations', (Free Press, New York, NY).

Fiske, A. P.: 1992, 'The Four Elementary Forms of Sociality: Framework for a Unified Theory of Social Relations', Psychological Review, 99, 689-723.

Fiske, A. P.: 2004, 'Relational Model Theory 2.0', In N. Haslam, Ed., RMs Theory: A Contemporary Overview, (Lawrence Erlbaum Associates, Mahwah, NJ), pp. 3-26.

Fiske, A. P., and Tetlock, P. E.: 1997, 'Taboo Tradeoffs: Reactions to Transactions that Transgress Spheres of Exchange', Political Psychology, 17, 255-294.

Foa, U. G.. and Foa, E. B.: 1974, 'Societal Structures of the Mind', (Thomas, Springfield, IL).

Gini, A.: 1998, 'Moral Leadership and Business Ethics', In J.B. Ciulla, Ed., Ethics, the Heart of Leadership, (Quorum Books, Westport, CT), pp. 27-45.

Goldman, A. I.: 1993: 'Ethics and Cognitive Science', Ethics, 103, 337-360.

Goodenough, W.H.: 1997, 'Moral Outrage: Territoriality in Human Guise', Zygon, 32,5-27.

Greenleaf, R. K.: 1977, 'Servant Leadership: A Journey into the Nature of Legitimate Power and Greatness', (Paulist Press, Mahwah, NJ).

Gudykunst, W. B.: 2001, 'Asian American Ethnicity and Communication', (Sage, Thousand Oaks, CA).

Haslam, N.: 2004, 'Research on the RMs: An Overview', In N. Haslam (ed.), RMs Theory: A Contemporary Overview, (Lawrence Erlbaum Associates, Mahwah, NJ), pp. 27-57. 
Jones, T.M., Felps, W.A. and Bigley, G.: 2007, 'Ethical Theory and Stakeholder-Related Decisions: The Role of Stakeholder Culture', Academy of Management Review, 32, 137155.

Kalshoven, K., Den Hartog, D. N., and De Hoogh, A. H. B.: in press, 'Ethical Leadership at Work Questionnaire (ELW): Development and Validation of a Multidimensional Measure', The Leadership Quarterly.

Kanungo, R. N.: 2001, 'Ethical Values of Transactional and Transformational Leaders', Canadian Journal of Administrative Sciences, 18, 257-265.

Kim, P. H., Ferrin, D. L., Cooper, C. D., and Dirks, K. T.: 2004, 'Removing the Shadow of Suspicion: The Effects of Apology vs. Denial for Repairing Ability- vs. Integrity-based Trust Violations', Journal of Applied Psychology, 89, 104-118.

Klein, S.: 2002, 'Ethical Business Leadership: Balancing Theory and Practice', (Peter Lang, New York, NY).

Kohlberg, L.: 1981. 'Essays on moral development (Vol. I): The philosophy of moral development', (Harper \& Row, San Francisco).

Lakoff, G.:2004, 'Don't think of an elephant! Know your values and frame the debate', (Chelsea Green).

Liden, R.C., Wayne, S.J., Zhao, H. and Henderson, D.: 2008, 'Servant Leadership: Development of a Multidimensional Measure and Multi-level Assessment', The Leadership Quarterly, 19, $161-77$.

Mayer, D. M., Kuenzi, M., Greenbaum, R., Bardes, M., and Salvador, R.: 2009, 'How low does Ethical Leadership flow? The Relative Effects of Top Management and Supervisors on Employee Ethical Behaviors and Job Attitudes', Organizational Behavior and Human Decision Processes, 108, 1-13. 
McGraw, A. P., and Tetlock, P. E.: 2005, 'Taboo Trade-offs, Relational Framing and the Acceptability of Exchange', Journal of Consumer Psychology, 15, 2-15.

McGraw, A. P., Tetlock, P. E., and Kristel, O. V.: 2003, 'The Limits of Fungibility: Relational Schemata and the Value of Things', Journal of Consumer Research, 30, 219-229.

Neubert, M. J., Carlson, D. S., Kacmar, K.M., Roberts J. A., and Chonko, L. B.: 2009, 'The Virtuous Influence of Ethical Leadership Behavior: Evidence from the Field', Journal of Business Ethics, 90, 157-170.

Rai, T. S., and Fiske, A. P.: in press, 'Moral Psychology is Relationship Regulation: Moral Motives for Unity, Hierarchy, Equality, and Proportionality', Psychological Review.

Resick, C. J., Hanges, P. J., Dickson, M. W., and Mitchelson, J. K.: 2006, 'A Cross-cultural Examination of the Endorsement of Ethical Leadership', Journal of Business Ethics, 63, 345359.

Russell, R. F., and Stone A. G.: 2002, 'A Review of Servant Leadership Attributes: Developing a Practical Model', Leadership and Organization Development, 23,145-57.

Sunar, D.: 2009, 'Suggestions for a New Integration in the Psychology of Morality', Social and Personality Psychology Compass, 3, 447-474.

Treviño, L. K., Brown, M., and Hartman, L. P.: 2003, 'A Qualitative Investigation of Perceived Executive Ethical Leadership: Perceptions from Inside and Outside the Executive Suite', Human Relations, 56, 5-37.

Trevino, L. K., and Weaver, G. R.: 2003, 'Managing Ethics in Business Organizations', (Stanford University Press, Stanford, CA).

Turner, N., Barling, J., Epitropaki, O., Butcher, V., and Milder, C.: 2002, 'Transformational Leadership and Moral Reasoning', Journal of Applied Psychology, 87, 304-311. 
van Dierendonck, D.: in press, 'Servant Leadership: A Review and Synthesis', Journal of Management, DOI: 10.1177/0149206310380462.

van Gils, S., van Quaquebeke, N., and van Knippenberg, D.: in press, 'Dancing in the Dark: Introducing and Exploring the Followers' Role in Unethical Organizational Behavior', In T. Hansbrough and B. Schyns (eds.), When Leadership Goes Wrong: Destructive Leadership, Mistakes and Ethical Failures, (Information Age Publishing, Greenwich, CT).

Whitehead, H.: 1993, 'Morals, Models, and Motives in a Different Light: A Rumination on Alan Fiske's Structures of Social Life', Ethos, 21, 319-356.

Weber, M.: 1978, 'Economy and Society', G. Roth and C. Wittich (eds), (University of California Press, Berkeley, CA). 


\section{Footnotes}

${ }^{1}$ In order to be considered an ethical leader within each RM, a leader must not only oversee the formation of contracts but also enforce adherence (Brown et al., 2005). What represents a punishment or a reward very much depends on the RM and its preos (Fiske, 1991). A follower with CS relationship could be punished with a exclusion from the common group and rewarded with the care and altruism. In AR, the leader determines might decrease the status position of the follower. In EM, each non-normative and behavior is punished with a similar negative or positive action. Finally in MP, the common metric might be used to calculate comparable rewards and punishments.

${ }^{2}$ There is also the possibility of no relation between leader and follower. This is comparable to the substitutes of leadership idea (Kerr \& Jermier, 1978). We do not discuss this idea here in much detail, because we are focusing only on relationships between leaders and followers. 


\begin{tabular}{|c|c|c|c|c|}
\hline & Communal Sharing & Authority Ranking & Equality Matching & Market Pricing \\
\hline $\begin{array}{l}\text { Underlying } \\
\text { guiding } \\
\text { relationship } \\
\text { principle }\end{array}$ & $\begin{array}{l}\text { Equivalence; people get } \\
\text { things according to needs } \\
\text { and give things according } \\
\text { to abilities }\end{array}$ & $\begin{array}{l}\text { Hierarchy; higher ranking } \\
\text { people get more }\end{array}$ & $\begin{array}{l}\text { Balance; things must be } \\
\text { equal }\end{array}$ & $\begin{array}{l}\text { Proportion; calculations of } \\
\text { cost-benefit ratios based } \\
\text { on value or utility metrics }\end{array}$ \\
\hline Morality & $\begin{array}{l}\text { "One-for-all and all-for- } \\
\text { one"; Altruism; sharing } \\
\text { generously with others; } \\
\text { love and care; fulfilling } \\
\text { needs; unity }\end{array}$ & $\begin{array}{l}\text { "Noblesse oblige"; } \\
\text { respect, deference, loyalty, } \\
\text { and obedience by } \\
\text { followers; responsibility, } \\
\text { security, protection and } \\
\text { direction by leader }\end{array}$ & $\begin{array}{l}\text { "Tit-for-Tat"; equal } \\
\text { treatment; reciprocal } \\
\text { revenge; everyone should } \\
\text { get the same thing }\end{array}$ & $\begin{array}{l}\text { "greatest good for the } \\
\text { wealthiest"; calculation of } \\
\text { utilities based on } \\
\text { negotiated contracts; costs } \\
\text { and benefits }\end{array}$ \\
\hline $\begin{array}{l}\text { Underlying } \\
\text { metric }\end{array}$ & Categorical distinction & Ordinal ranking & Interval comparisons & Ratios \\
\hline $\begin{array}{l}\text { Fairness } \\
\text { standards }\end{array}$ & Need & Power/Duty & Equality & Equity \\
\hline $\begin{array}{l}\text { Followers } \\
\text { mental model of } \\
\text { ethical } \\
\text { leadership }\end{array}$ & $\begin{array}{l}\text { Leader and follower must } \\
\text { belong to a common } \\
\text { psychological group in } \\
\text { which resources (e.g., } \\
\text { time, needs) are shared } \\
\text { and leadership is caring } \\
\text { about others and showing }\end{array}$ & $\begin{array}{l}\text { Leader must guid and } \\
\text { provide security for } \\
\text { followers and treat all } \\
\text { parties according to } \\
\text { hierarchical rank }\end{array}$ & $\begin{array}{l}\text { Leadership must be even- } \\
\text { handed, provide equal } \\
\text { opportunities, equal voice } \\
\text { and equal contributions }\end{array}$ & $\begin{array}{l}\text { Leadership through a } \\
\text { negotiated contract } \\
\text { between the follower and } \\
\text { the leader with a common } \\
\text { metric (e.g., money). } \\
\text { Follower considers cost- } \\
\text { benefit calculations to }\end{array}$ \\
\hline
\end{tabular}


Relational Models and Ethical Leadership 32

altruistic behavior determine appropriate

actions
Low to Mid

Mid to High

High

Table 1. Overview on RMT, connected morality and fairness issues, as well as links with leadership styles 


\section{Publications in the ERIM Report Series Research* in Management}

\section{ERIM Research Program: "Organizing for Performance"}

2011

Chain Interdependencies, Measurement Problems, and Efficient Governance Structure:

Cooperatives versus Publicly Listed Firms

Li Feng and George Hendrikse

ERS-2011-001-ORG

http://hdl.handle.net/1765/22720

Using a Relational Models Perspective to Understand Normatively Appropriate Conduct in Ethical Leadership

Steffen R. Giessner and Niels van Quaquebeke

ERS-2011-002-ORG

http://hdl.handle.net/1765/22721

Tango in the Dark: The Interplay of Leader's and Follower's Level of Self-Construal and its Impact on Ethical Leadership Suzanne van Gils, Niels van Quaquebeke, and Daan van Knippenberg ERS-2011-005-ORG

http://hdl.handle.net/1765/22724

* A complete overview of the ERIM Report Series Research in Management: https://ep.eur.nl/handle/1765/1

ERIM Research Programs:

LIS Business Processes, Logistics and Information Systems

ORG Organizing for Performance

MKT Marketing

F\&A Finance and Accounting

STR Strategy and Entrepreneurship 